\title{
Determinação de Estruturas Químicas
}

\author{
João Carlos de Andrade \\ Rogério Custodio \\ roger@iqm.unicamp.br \\ Universidade Estadual de Campinas, Instituto de Química
}

\begin{abstract}
Palavras-Chaves
Geometria molecular

Difração

Raios-X estrelas e corpos celestes e especular sobre a constituição do universo, sua origem e seus limites. Nos próximos capítulos serão abordados aspectos básicos de diferentes recursos espectroscópicos e de algumas de suas possíveis aplicações no conhecimento da natureza microscópica.
\end{abstract}

Celas unitárias

Retículos de Bravais

Estruturas químicas

Resumo

Histórico do Artigo

Criado em Junho de 1997

Atualizado em Março de 2000
A interação da radiação eletromagnética com a matéria corresponde a um dos aspectos mais importantes da ciência. Através dessa interação obtemos informações da natureza microscópica da matéria e da qual especulamos e formulamos modelos com os quais procuramos prever possíveis tendências a serem apresentadas por substâncias de interesse, conhecidas ou desconhecidas. Curiosamente, é através da espectroscopia e do conhecimento da matéria microscópica, que podemos sondar astros,

\section{Geometria molecular}

Para o cientista, atualmente, parece quase impossível imaginar como a ciência estaria se não fossem desenvolvidos os conceitos de átomo e molécula. Entretanto, no início deste século era perfeitamente possível que um bom químico tivesse sérias dúvidas a respeito da viabilidade desse modelo. A proposta da teoria atômica publicada por Dalton no seu livro, "A New System of Chemical Philosophy", em 1808, não deixou de receber resistência por parte da comunidade científica da época. Químicos como Ostwald desenvolviam estudos abrangentes sem mencionar qualquer teoria que pudesse sugerir a possibilidade da existência de átomos ou moléculas.

Com as descobertas das radiações e dos elétrons no final do século XIX tornava-se possível imaginar e mesmo começar a medir eventos que sugeriam a possibilidade de uma descontinuidade na matéria. Seguiu-se o famoso experimento de $\boldsymbol{R}$ utherford, a hipótese da quantização da energia pela teoria da radiação do corpo negro de Plank, a confirmação desta pelo efeito fotoelétrico e o espalhamento Compton, o princípio da dualidade ondapartícula de De Broglie, provado experimentalmente por difração de elétrons e alguns outros fatos experimentais que foram solucionados admitindo-se que havia uma descontinuidade na matéria e na energia. $\mathrm{O}$ resultado de todas estas informações culminaram com a criação, em 1927, do modelo atômico de Schrödinger.

Com a introdução da idéia de átomos, não foi muito difícil aceitar-se a existência das moléculas, entidades que podem ser definidas como agrupamentos específicos de átomos, unidos por fortes forças de interação eletrostática. A característica mais importante a ser destacada é que cada molécula comporta-se como uma unidade 
independente de outra, isto é, ela preserva as propriedades do sistema. Este tipo de consideração é bastante viável quando observamos sistemas gasosos. Mas, a medida que condensamos a matéria, isto é, a medida que fazemos com que as moléculas fiquem mais próximas umas das outras, intensifica-se uma série de interações inter-moleculares que produzem desvios em algumas propriedades químicas e físicas em relação ao estado gasoso.

Duas perguntas surgem naturalmente quando pensamos em moléculas. A primeira diz respeito às forças que mantém unido o limitado grupo de átomos, ou seja, por que as moléculas apresentam composição atômica constante? A segunda diz respeito à necessidade de saber se a distribuição dos átomos na molécula é um fator relevante ou, em outras palavras, se a geometria molecular representa um papel importante nas propriedades dos sistemas macroscópicos.

Com o experimento de Rutherford a hipótese de que a natureza dos átomos é elétrica foi enfatizada, sendo estes constituídos por partículas com carga positiva, negativa e partículas sem carga, logo as forças de interação seriam de natureza elétrica, o que responderia muito superficialmente a primeira pergunta.

Para responder a segunda, utilizaremos alguma informação experimental. Vamos supor que temos três compostos A, $\mathrm{B}$ e $\mathrm{C}$ que apresentam as seguintes propriedades.

\begin{tabular}{|l|l|l|}
\hline Molécula & Ponto de Fusão $\left({ }^{\circ} \mathbf{C}\right)$ & Ponto de Ebulição $\left({ }^{\circ} \mathbf{C}\right)$ \\
\hline A & $-126,0$ & 97,0 \\
\hline B & $-86,0$ & 82,5 \\
\hline C & --- & 10,8 \\
\hline
\end{tabular}

Estes dados sugerem que os três compostos são diferentes. Se fizermos então uma análise elementar de A, B e C observaremos que as moléculas dos três compostos apresentam a mesma composição: 3 átomos de carbono, 8 átomos de hidrogênio e 1 átomo de oxigênio. Com a informação de que os três compostos são constituídos pelos mesmos tipos e número de átomos e que suas propriedades são completamente diferentes, podemos concluir que o fator responsável por essa diferença de propriedades provém dos diferentes arranjos geométricos dos átomos nas três moléculas, que normalmente definimos como isomeria. E é exatamente isto o que se observa: A e B são compostos caracterizados atualmente como álcoois e C corresponde a um éter. Sua fórmula pode ser dada pelas seguintes representações:

\begin{tabular}{|l|l|}
\hline $\mathrm{A}$ & $\mathrm{H}_{3} \mathrm{C}-\mathrm{CH}_{2}-\mathrm{CH}_{2} \mathrm{OH}$ \\
\hline $\mathrm{B}$ & $\mathrm{H}_{3} \mathrm{C}-\mathrm{HCOH}-\mathrm{CH}_{3}$ \\
\hline $\mathrm{C}$ & $\mathrm{H}_{3} \mathrm{C}-\mathrm{CH}_{2}-\mathrm{O}-\mathrm{CH}_{3}$ \\
\hline
\end{tabular}

Para termos maior conhecimento de como variam as propriedades macroscópicas com o arranjo geométrico dos átomos, seria necessário que conhecêssemos os comprimentos e ângulos de ligação de cada molécula e neste trabalho, o que mostraremos é exatamente como isto é feito, ou melhor, as técnicas experimentais que nos permitem medir essas grandezas.

\section{A natureza das medidas experimen-} tais

Partindo-se da consideração de que átomos e moléculas são constituídos por prótons, elétrons e neutrons, que apresentam cargas elétricas características, podemos imaginar que a medida de parâmetros geométricos, ou seja, da posição dos átomos em uma molécula, estará diretamente relacionada com a interação de uma entidade qualquer com essas partículas. Uma observação evidente a ser feita é que essa entidade que perturbará as referidas partículas deverá ter dimensões compatíveis com as dimensões atômico-moleculares. Genericamente podemos caracterizar duas entidades utilizáveis para essa finalidade: radiações eletromagnéticas e partículas subatômicas (prótons, neutrons, elétrons, etc.).

Colocando-se uma partícula carregada eletricamente em um campo elétrico ou magnético oscilante, a partícula em questão sentirá a perturbação de uma força que variará em função das oscilações do campo aplicado. Radiações eletromagnéticas são aquelas constituídas por composição de campos elétricos e magnéticos que poderão exercer perturbações em sistemas eletricamente carregados. James C.Maxwell mostrou matematicamente em 1860 que a luz apresentava as características de uma radiação eletromagnética. Logo, podemos esperar que a luz poderá ser utilizada como instrumento de medida da posição aproximada dos átomos em qualquer sistema material. Mas, luz visível corresponde apenas a uma faixa extremamente limitada do que se chama de espectro de radiação eletromagnética. A Figura 1 mostra a grande faixa de radiação disponível para análise de estruturas moleculares. Podemos observar que o espectro eletromagnético está dividido em várias regiões com nomes especiais.

Devemos dizer que esta divisão é feita basicamente em função de dois fatores:

1. o tipo de fonte que gera cada radiação e

2. o tipo de alteração que a respectiva radiação causa nos sistemas atômico-moleculares. 


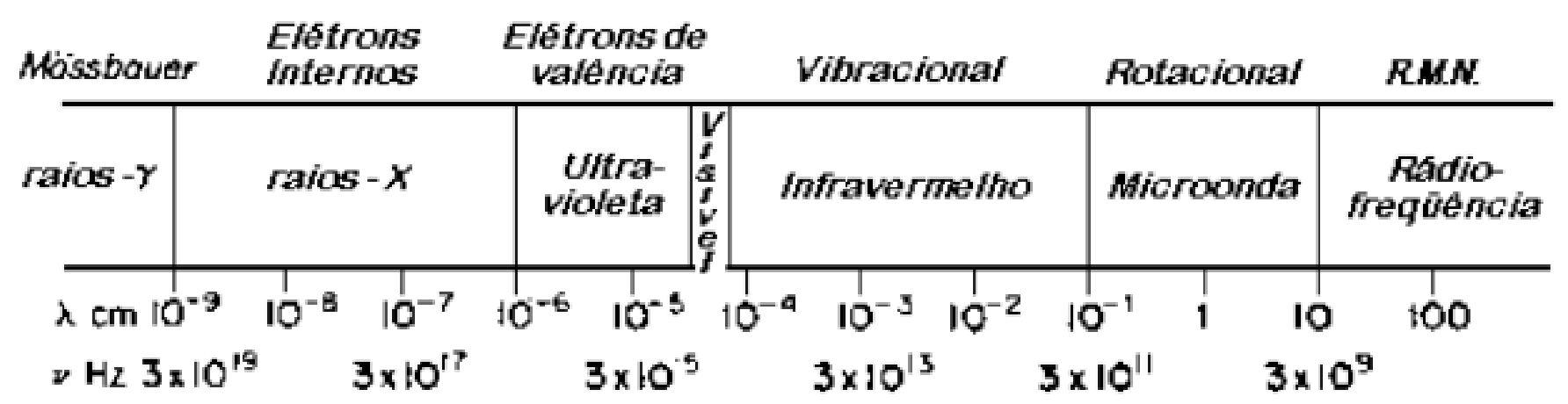

Figura 1 - Espectro de radiação eletromagnética.

Sobre a utilização de partículas sub-atômicas devemos dizer que é o caráter ondulatório das mesmas (dualidade onda-partícula de De Broglie) o fator mais importante na determinação da geometria molecular.

O método experimental básico utilizado, tanto no caso de radiações eletromagnéticas quanto no de partículas sub-atômicas, apresenta as características de um dos experimentos mais geniais já idealizados: o experimento de Rutherford. Em resumo, geralmente teremos uma fonte de radiação ou de partículas que incidirão sobre a amostra a ser analisada, atravessando-a ou refletindo-se sobre a superfície, e um detector que procurará observar quanto da radiação foi absorvida ou onde se encontram as maiores concentrações de partículas espalhadas. $\mathrm{O}$ que leva à diferenciação das várias técnicas experimentais existentes são refinamentos do método de Rutherford, com a finalidade de melhorar a precisão das medidas obtidas.

\section{Métodos de difração}

Os métodos de difração mais conhecidos são aqueles que utilizam raios- $\boldsymbol{X}$, elétrons e neutrons. Para este tipo de método, o aspecto mais importante a ser considerado é o de que, sejam radiações eletromagnéticas, sejam partículas sub-atômicas, as propriedades mais importantes a serem consideradas para se identificar a posição dos átomos nas moléculas são os efeitos de interferência e difração de ondas. Seguindo a metodologia proposta por Huygens, sabemos que se uma frente de onda incidir sobre um conjunto de fendas ou uma grade de difração (placas com uma série de ranhuras paralelas e eqüidistantes) o resultado será o que se conhece como uma figura de difração. As características desta figura são de que ela apresenta regiões de máxima intensidade de radiação intercaladas com regiões de mínima intensidade. A natureza deste efeito se baseia no princípio de sobreposição de ondas. A Figura 2 mostra o efeito de difração após a passagem de um feixe de radiação por fendas separadas por uma distância $d$.
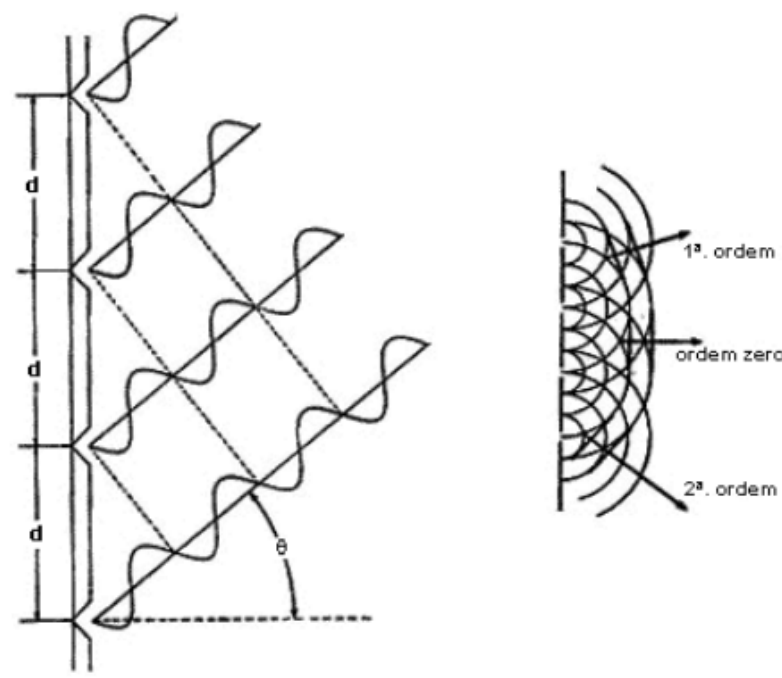

Figura 2 - Efeito da difração da luz ao passar por fendas separadas por uma distância d.

O primeiro máximo de difração é o que apresenta maior intensidade, o segundo apresenta intensidade menor e assim sucessivamente. Em resumo, quanto menor o ângulo $\theta$ em que aparece o máximo de intensidade, maior será a sua intensidade. O máximo na região central é denominado de máximo de ordem zero, o primeiro máximo vizinho ao central é caracterizado como sendo de primeira ordem, o segundo máximo como sendo de segunda ordem e assim sucessivamente. Matematicamente Huygens mostrou que esse padrão de interferência de ondas obedecia a seguinte relação:

$$
n \lambda=d \operatorname{sen} \theta \quad \text { equação (1) }
$$

onde $n$ representa a ordem do máximo de intensidade, $\lambda$ é o comprimento de onda da radiação utilizada, $d$ é 
a separação das fendas ou entre as linhas das grades de difração e $\theta$ o ângulo definido na Figura 2. Desta expressão observamos que se mantivermos $\lambda$ constante $\mathrm{e}$ aumentarmos $d$, o $\operatorname{sen} \boldsymbol{\theta}$ tenderá a zero, o que mostra que só haverá figura de difração se o valor de $d$ apresentar as mesmas dimensões de $\lambda$.

Uma vez que adquirimos os aspectos que governam os processos de difração, vamos passar diretamente aos métodos que utilizam tal efeito para determinar distâncias e ângulos interatômicos.

\section{Raios X}

Até o ano de 1912 as informações sobre estruturas cristalinas eram quase inexistentes. Um outro problema também sem solução eram informações sobre a natureza dos raios-x. A única sugestão sobre estrutura de cristais foi dada por RenéJ.Hauy em 1784, propondo que a forma regular dos cristais deveria refletir um arranjo regular interno de pequenos cubos ou poliedros, os quais ele denominou de "moléculas integrantes" da substância.

Max von Laue, diante dos dois problemas, sugeriu que se os raios-x tivessem caráter ondulatório, seu comprimento de onda poderia ser regulado em uma dimensão tão pequena quanto a distância entre os átomos nos cristais. Consequentemente, fazendo-se um feixe de raios- $x$ atravessar um cristal, deveríamos observar uma figura de difração. A Figura 3 mostra que a hipótese de von Laue estava correta.

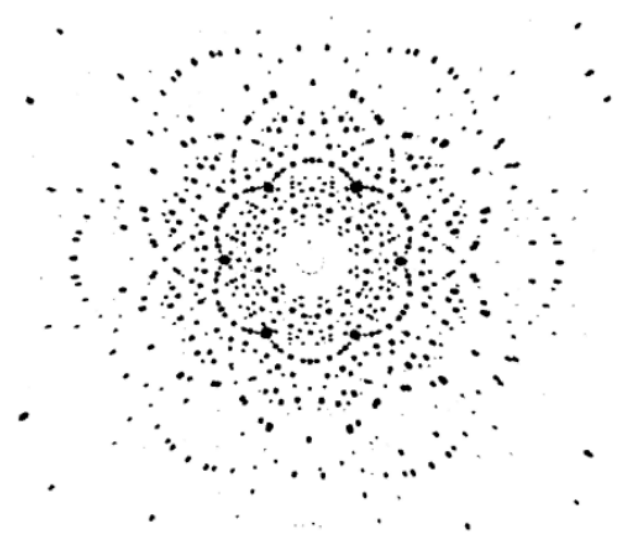

Figura 3 - Figura da difração produzida pela passagem de raio-x através de um cristal.

A pergunta que se faz quando se olha para a Figura 3 é: de que maneira poderemos tirar informações sobre a estrutura cristalina? $\mathrm{Ou}$, o que exatamente nos mostra as manchas da Figura 3?
A primeira coisa é que as manchas apresentam posições definidas e por mais fotos que sejam tiradas do cristal na mesma posição, será encontrado sempre o mesmo padrão de manchas. Aceitando-se que os raios-x apresentam caráter ondulatório e se os raios-x produzem interferência construtiva e destrutiva este deverá obedecer a relação dada pela Eq.1. Em outras palavras, para aparecerem máximos de intensidade em uma figura de difração, dois feixes luminosos devem estar defasados em um número inteiro do comprimento de onda. Mas, em um cristal, só poderemos obter tal efeito se os raios-x forem espalhados por pontos fixos no cristal, que serão átomos, íons ou moléculas. Desta forma, como pode ser observado na Figura 4, verificou-se que os máximos e mínimos apareciam em um arranjo cristalino tridimensional, obedecendo as relações:

$$
\begin{aligned}
& a\left(\cos \phi_{1}-\cos \phi_{0}\right)=h \lambda \\
& b\left(\cos \phi_{2}-\cos \phi_{0}^{\prime}\right)=k \lambda \quad \text { equação (2) } \\
& c\left(\cos \phi_{3}-\cos \phi_{0}^{\prime \prime}\right)=l \lambda
\end{aligned}
$$

onde são os ângulos $\phi_{0}$, $\phi_{0}$ ' e $\phi_{0}$ " incidentes do raio-x; $\phi_{1}$, $\phi_{2}$ e $\phi_{3}$ são os ângulos de espalhamento; $\lambda$ o comprimento de onda do raio-x; $h, k$ e $l$ correspondem a números inteiros de comprimentos de onda e $a, b$ e $c$ são distâncias de espaçamento entre os pontos regulares do cristal.

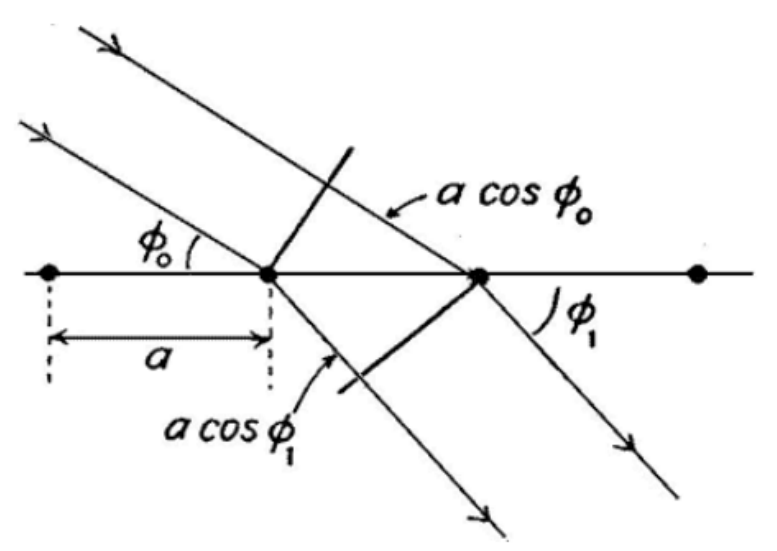

Figura 4 - Condições de máximos e mínimos para o método de Lowe.

Pouco tempo depois, Willian e Lowrence Bragg executaram certas modificações no método de análise de cristais por raios-x. A primeira foi a de detectar o feixe de raios-x utilizando uma câmara de ionização; no método de Laue utilizava-se placas fotográficas. O detector dos Bragg, apesar de ser mais preciso, era mais lento e consequentemente mais incômodo, o que levou o método de Laue a popularizar-se mais até meados de 1960. Outra modificação foi a de utilizar um feixe monocromático de 
raios-x e também detectar não os feixes que atravessavam o cristal, mas sim aqueles que eram refletidos pela superfície do mesmo.

A condição para o máximo na intensidade de difração (ver Figura 5) sugere a equação:

$$
n \lambda=2 d \operatorname{sen} \theta \quad \text { equação (3) }
$$

onde $\theta$ é o ângulo definido na Figura 5 , $\lambda$ o comprimento de onda do raio-x monocromático, $d$ o espaçamento entre dois planos do cristal e $n$ a ordem dos máximos de intensidade da figura de difração.

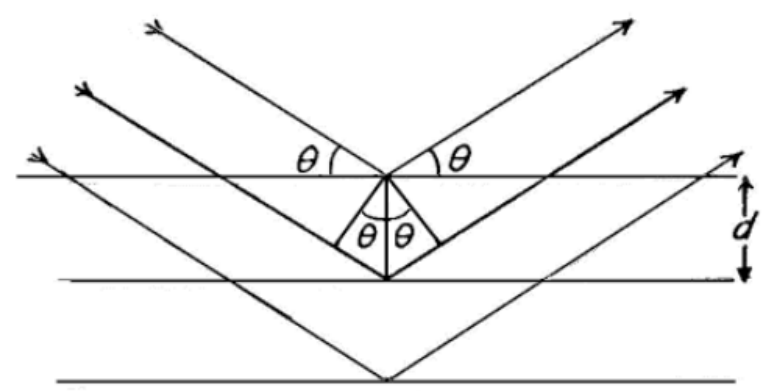

Figura 5 - Condições de máximos e mínimos obtidos através da difração de raios-x empregando o esquema sugerido pelos Bragg.

Podemos perceber que, tanto na Eq.2 quanto na Eq.3, surgem medidas de distâncias entre planos que contém átomos, moléculas ou íons. Esses planos são definidos em função de modelos cristalográficos. Ressuscitando o pensamento de Hauy, procurou-se criar em um sistema onde haviam certas repetições nas posições de suas partículas, uma entidade que pudesse ser repetida indefinidamente em qualquer direção e reproduzir a estrutura de um cristal. Em um sistema bidimensional uma das possibilidades de plano cristalino seria $o$ apresentado na Figura 6. Qualquer das celas (a,b), (a,b') ou (a”,b”) são possíveis celas unitárias.

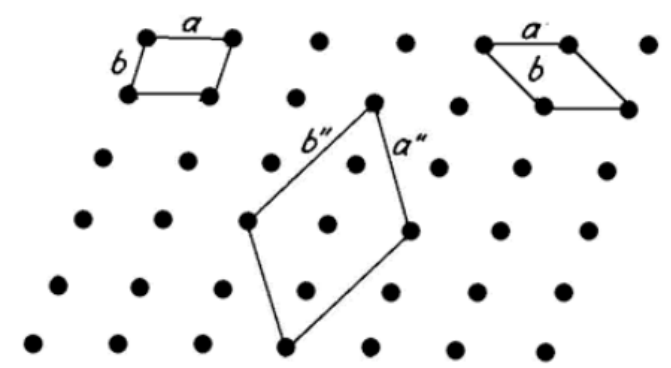

Figura 6 - Possíveis celas unitárias em um sistema bidimensional.

Convencionou-se admitir como cela padrão aquela que apresentasse menor área. Entretanto, um cristal sempre apresenta uma estrutura tridimensional que se repete indefinidamente em qualquer direção do espaço. Este problema já havia sido resolvido por Bravais em 1848, que demonstrou que todos os possíveis reticulados espaciais poderiam ser agrupados em 14 tipos. A Figura 7 mostra os reticulados de Bravais.
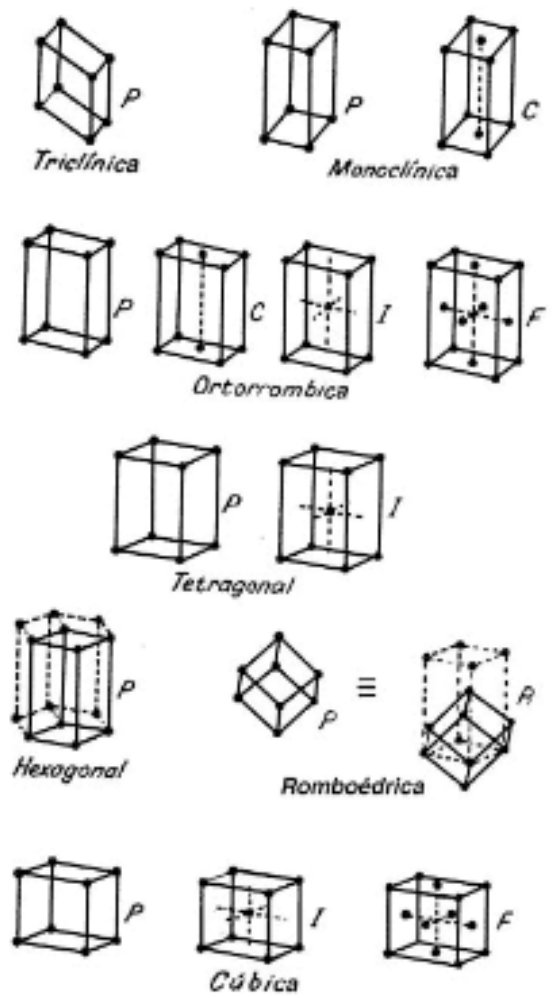

Figura 7 - Os reticulados de Bravais.

Por estes reticulados poderemos passar uma série de planos que são caracterizados por índices chamados de Miller e representados pelas letras $h, k$ e $l$. A Figura 8 mostra os planos que caracterizam espaçamentos em alguns dos reticulados de Bravais.

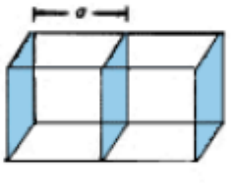

$a_{100}=0$
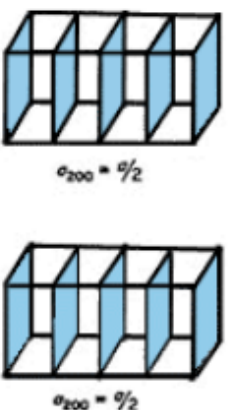

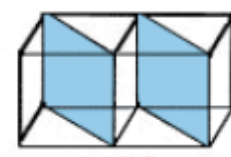

$a_{100}=\frac{1}{2} \sqrt{2} 0$

(o)

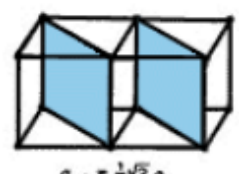

(b)

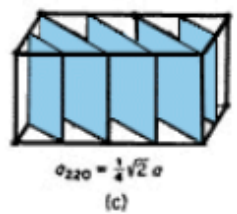

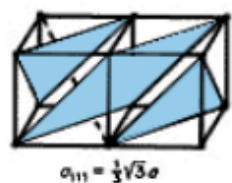

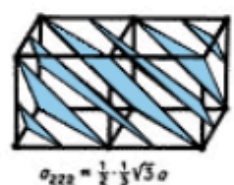

$0_{223}=\frac{1}{2} \div \frac{1}{3} \sqrt{3}$ 。

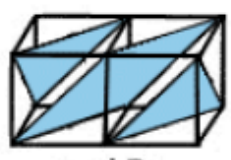

$a_{11}=\frac{1}{3} \sqrt{3} 0$
Figura 8 - Espaçamentos entre planos de átomos em alguns reticulados de Bravais. 
Utilizando-se geometria euclidiana poderemos mostrar que para um reticulado cúbico a distância entre dois planos é dada por:

$$
d_{h k l}=\frac{a_{0}}{\left(h^{2}+k^{2}+l^{2}\right)^{1 / 2}} \quad \text { equação (4) }
$$

Que combinada com a Eq.3 nos fornece:

$$
\operatorname{sen}^{2} \theta=\frac{\lambda}{4 a_{0}^{2}}\left(h^{2}+k^{2}+l^{2}\right)_{\text {equação }(5)}
$$

Desta forma, poderemos caracterizar cada máximo de difração com um conjunto de valores $(h k l)$. Uma vez que podemos caracterizar cada máximo em função de $(h k l)$ poderemos conhecer valores de distâncias entre os átomos nas celas unitárias. Mas, resta-nos um problema: como poderemos caracterizar uma cela unitária? Vamos verificar o caso clássico do $\mathrm{NaCl}$ e do $\mathrm{KCl}$.

Pegamos um mono cristal de $\mathrm{NaCl}$ e fazemos incidir sobre ele um feixe monocromático de raios-x. Procuramos variar o ângulo de incidência e detectar os máximos de difração em vários planos do cristal (Figura 9). Utilizando-se a Eq. 5 obteremos uma série de intervalos como função de $\mathrm{a}_{0}$.

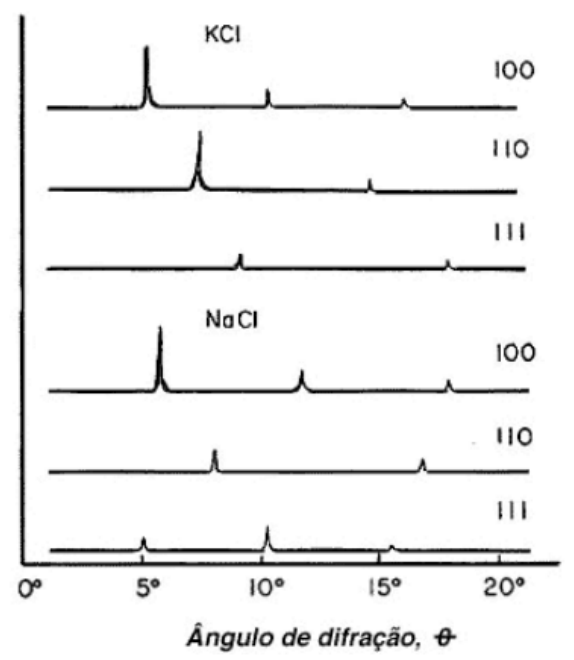

Figura 9 - Padrão de difração de raios-x obtidos pelo método de Bragg para alguns planos do cristal de $\mathrm{KCle} \mathrm{NaCl}$.

Por exemplo, o plano 100 (para compreender o significado da notação "100" veja a Figura 10 e a Figura 8) apresenta máximos equidistantes em um valor de $\mathrm{a}_{\mathrm{n}} / 2$. Para o plano 110 observamos que esta medida é de $(\sqrt{2} / 2) \mathrm{a}_{0}$ e para o plano 111 a distância observada é de $(\sqrt{3} / 3) \mathrm{a}_{0}$, mas estas são exatamente as relações entre planos que cortam um reticulado cúbico de face centrada (ver Figura 8). Agora pela escolha adequada dos valores de $\mathrm{h}, \mathrm{k}$ e $\mathrm{l}$ teremos o valor de $\mathrm{a}_{0}$ que nos fornecerá os comprimentos das distâncias interatômicas. Fazendo-se a mesma análise para o $\mathrm{KCl}$ verificaremos que o mesmo apresenta reticulado cúbico.
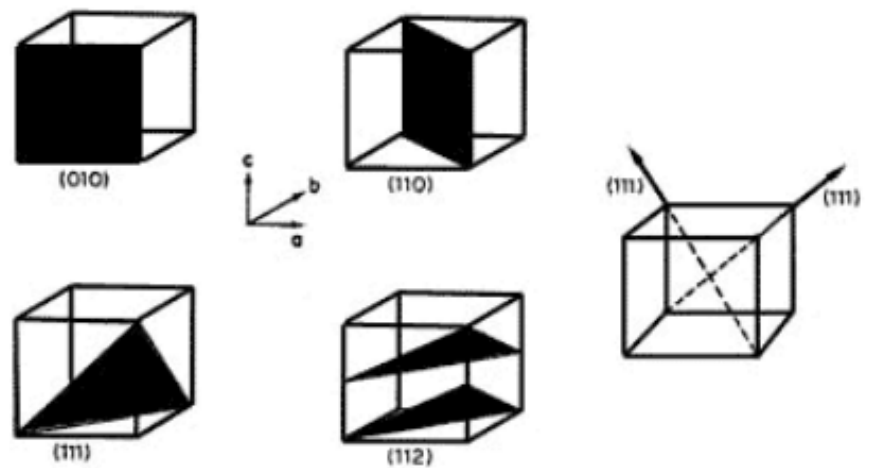

Figura 10 - Exemplo ilustrativo da notação utilizada para caracterizar planos de átomos em um cristal.

Mas, será apenas esta informação que poderemos retirar do raio-x? Não, temos agora que utilizar os valores das intensidades para retirar informações mais seguras sobre a estrutura de moléculas, pois até agora só conseguimos valores da posição de átomos no cristal, mas não de átomos em moléculas.

A intensidade dos raios-x é diretamente proporcional à amplitude de suas ondas e esta é proporcional a um fator estrutural que é função dos planos $(h k l)$ e será representado como $\mathrm{F}(h k l)$. Este fator estrutural inclui o efeito do espalhamento de todos os átomos em uma cela unitária e pode ser representado matematicamente como:

$$
F(h k l)=\sum_{i} F_{i} \cos 2 \pi\left[\frac{h x_{i}}{a}+\frac{k y_{i}}{b}+\frac{l z_{i}}{c}+B_{i}(h k l)\right] \text { equação (6) }
$$

onde $i$ designa determinado átomo; $F_{i}$ o poder de espalhamento desse átomo; a, b e c são as dimensões da cela unitária; $x_{i}, y_{i}$ e $z_{i}$ as coordenadas do átomo $i$ e $B_{i}$ o ângulo de fase que está relacionado com a distância que o átomo $i$ está do ponto tomado como origem da cela unitária.

Para um cristal desconhecido, postula-se sua estrutura e calcula-se $\mathrm{F}(h k l)$, comparando-se com o valor obtido experimentalmente. Faz-se uma revisão da estrutura até que haja concordância entre os valores calculados com os experimentais. Posterior informação é obtida através de observação da densidade eletrônica, por intermédio de análise utilizando-se o método de Fourier. 
Como sabemos, raios-x existem por causa de alterações no comportamento dos elétrons internos em átomos, moléculas ou íons, logo deve-se imaginar que talvez seja possível conhecer a densidade eletrônica de sistemas atômicos ou moleculares através de uma relação desta com a intensidade observada.

A densidade eletrônica $\rho$ em um cristal é repetida para cada cela unitária e toda função periódica pode ser representada por uma série de Fourier, logo:

$$
\rho(x, y, z)=\sum_{h} \sum_{k} \sum_{l} c_{h k l} \cos 2 \pi\left[\frac{h x}{a}+\frac{k y}{b}+\frac{l z}{c}+\varepsilon(h k l)\right] \text { equação (7) }
$$

que combinando-se com a Eq.6 nos fornece:

$$
\rho(x, y, z)=\frac{1}{U_{0}} \sum_{h} \sum_{k} \sum_{l} F_{h k l} \cos 2 \pi\left[\frac{h x}{a}+\frac{k y}{b}+\frac{l z}{c}+\varepsilon(h k l)\right] \text { equação }
$$

onde $\mathrm{U}_{0}$ é o volume da cela unitária.

A Equação 8 pode ser usada agora para calcular o mapa de densidade eletrônica de uma molécula em um cristal. Quando um mapa de boa resolução é obtido, os pontos de máxima densidade eletrônica correspondem ao centro dos átomos e, consequentemente, às suas posições. $\mathrm{O}$ grande problema no cálculo desses mapas é a obtenção do fator que representa o ângulo de fase dos raios-x, sendo este o problema crítico no método. Quando este problema é considerado como quase solucionado, imaginamos que o mapa de densidade eletrônica mostrará a posição exata dos átomos em uma molécula. Isto não é verdade, pois para termos uma densidade eletrônica precisa, teríamos que estender a série de Fourier ao infinito e isto é impossível. Logo, qualquer mapa de densidade eletrônica apresenta um erro. Um refinamento da técnica poderia ser obtido pela inclusão de métodos de mínimos quadrados que tornariam o erro da medida muito pequeno. Um exemplo de mapa de densidade eletrônica pode ser observado na Figura 11.

O método de determinação de estruturas por raios-x é um método característico para ser aplicado em determinação de geometria de moléculas no estado sólido. $\mathrm{O}$ método clássico de raios-xera comumentelimitado pela necessidade de que a amostra a ser analisada fosse um monocristal da substância. Esta condição limitava consideravelmente a aplicação da técnica a um número muito pequeno de substâncias. Para contornar tal inconveniente desenvolveuse o método de análise utilizando-se amostras em pó e observou-se que informações precisas eram também obtidas desta maneira.

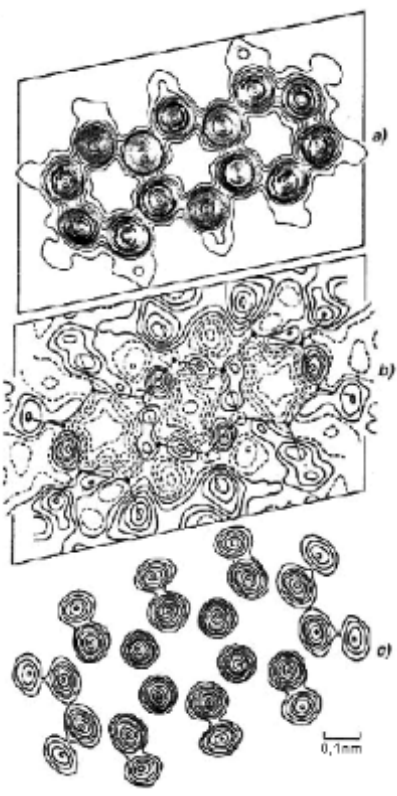

Figura 11 - Estrutura do antraceno obtida através de: a) raio-x; b) difração de elétrons; c) difração de neutrons.

Mas, do que depende a precisão nas medidas de parâmetros geométricos por raios- $x$ ? $\mathrm{O}$ fator que primeiro deve ser controlado é a temperatura, pois esta alterará o movimento vibracional dos átomos nos cristais ou moléculas, alterando o valor dos parâmetros geométricos de equilíbrio.

Outro aspecto desfavorável do método de raios-x é que, uma vez que esta técnica depende das camadas eletrônicas, átomos que possuem muitos elétrons dificultarão a detecção daqueles que apresentam menor número dos mesmos. O caso mais extremo é o átomo de hidrogênio, que através de mapas de densidade eletrônica, ou melhor, da técnica de raios-x, não pode ser adequadamente visualizado. Um exemplo disto pode ser visto na Figura 11a.

Observamos que as posições dos átomos de hidrogênio são um tanto difusas e mal definidas em relação aos outros átomos.

Para cristais simples o método oferece distância intereletrônicas extremamente precisas. Para alguns materiais entretanto, não tem sido possível estabelecer qualquer estrutura, uma vez que as aproximações utilizadas, principalmente no que diz respeito ao ângulo de fase, não convergem para a solução exata.

A despeito dos problemas aqui comentados, o crescente número de estruturas determinadas por este método é cada vez maior. Exemplo disto pode ser melhor visualizado na Figura 12, que mostra o número de publicações de estruturas contendo carbono entre 1935 e 1968. 


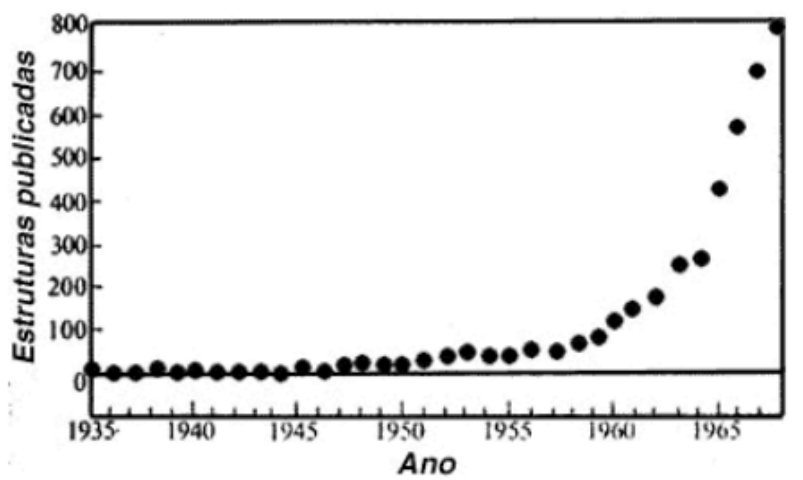

Figura 12 - Número de estruturas determinadas através de raio-x em função do ano, cobrindo um intervalo compreendido entre 1935 a 1968.

\section{Difração de nêutrons}

Como pudemos ver anteriormente, a incidência de radiações eletromagnéticas que possuem comprimentos de onda próximos ao valor das distâncias interatômicas sobre um cristal qualquer produz figuras de difração, das quais é possível obtermos informações precisas sobre a posição dos átomos em um cristal. Se relembrarmos da relação de De Broglie de que para cada partícula que se move com determinada velocidade está associado um comprimento de onda, podemos imaginar que estas partículas produzirão também figuras de difração. Experimentalmente este fato foi confirmado por J.P.Thomson, filho de J.J.Thomson, e por A.Reid que conseguiram figuras de difração de elétrons através de uma folha de ouro. Uma curiosidade sobre estes experimentos é que J.J.Thomson ganhou o prêmio Nobel por mostrar que o elétron apresentava características de partícula e J.P.Thomson ganhou por mostrar que o elétron apresentava características ondulatórias.

Com a demonstração de que partículas aceleradas podem produzir figuras de difração, iniciou-se o estudo de estruturas moleculares da mesma forma que com os raios-x. As partículas comumente usadas geraram as técnicas de difração de neutrons e de elétrons. Nesta etapa comentaremos algumas características do método de difração de neutrons.

A primeira característica deste método é que neutrons que apresentam comprimento de onda próximo de $1.10^{-10} \mathrm{~m}$ devem possuir velocidades de $4000 \mathrm{~m} \mathrm{~s}^{-}$

1 aproximadamente. Para termos idéia da magnitude desta velocidade, podemos dizer que a velocidade de uma molécula de hidrogênio em um gás a $250^{\circ} \mathrm{C}$ é de
$1768 \mathrm{~m} \mathrm{~s}^{-1}$. A fonte comumente utilizada para produzirse neutrons com tais velocidades são reatores nucleares. Uma vez que os reatores expelem neutrons com diferentes velocidades, uma forma adequada de produzir-se uma distribuição gaussiana de velocidades é passarmos o feixe de neutrons através de uma substância denominada moderador. Um dos mais comuns é o carbono na forma de grafite.

Mas, por que é interessante homogeneizar a velocidade dos neutrons? Porque quanto mais estreita for a faixa de velocidades, mais estreita será a faixa de intensidade. Tendo controlado a velocidade do feixe de neutrons poderemos produzir figuras de difração do tipo Laue.

Entretanto, um problema ocorria na fase de detecção dos neutrons. Originalmente fazia-se a detecção através de chapas fotográficas, o que era um fator limitante na utilização do método, pois os neutrons não produzem respostas bem definidas em chapas fotográficas. Atualmente, uma série de contadores baseados em reações nucleares suprimiu esta dificuldade. Basicamente, procura-se fazer o neutron colidir com algum átomo e a interação com este liberará radiação gama ou prótons ou outra partícula carregada, que será facilmente detectada por câmaras de ionização.

Uma das desvantagens é que o detector necessita de uma fonte suficientemente intensa para produzir boas figuras de difração, o que limita a técnica a poucos laboratórios do mundo.

As vantagens desta técnica em relação aos raios-x é que a mesma permite, ao contrário dos raios-x, detectar com excelente precisão a posição de átomos leves como o hidrogênio e deutério. Outra grande vantagem é que esta técnica é a única que permite obter qualquer informação sobre a estrutura magnética de sólidos.

A grande diferença entre o raio-x e a difração de neutrons é que o primeiro interage com os elétrons dos átomos, enquanto que os neutrons interagem diretamente com os núcleos. Desta interação direta com os núcleos pode ocorrer três tipos de espalhamento:

1. elástico,

2. magnético,

3. inelástico.

O primeiro tipo de espalhamento é o mais simples. Os neutrons colidem com os núcleos e são espalhados sem qualquer alteração significativa de intensidade ou velocidade com o ângulo de deflexão. Como os núcleos 
atômicos apresentam ondas de $1.10^{-10} \mathrm{~m}$ aproximadamente, não percebemos qualquer efeito de interferência devido às diferentes partes do núcleo.

O poder dispersante dos neutrons por distintos elementos químicos é bastante diferente do raio-x. Neste último, quanto maior o número de elétrons em um átomo, maior será seu poder de dispersão. Com os neutrons já não ocorre a mesma coisa. Pode-se provar que a amplitude $b$ de um feixe de neutrons espalhado é proporcional à raiz cúbica do número de massa do núcleo atômico. Desta forma, podemos ver que o poder dispersante dos neutrons aumentará muito lentamente ao passar de núcleos leves para pesados. Um exemplo deste efeito pode ser facilmente verificado para dois elementos com número de massa 10 e 200. Os valores de b são respectivamente: $0,33 \times 10^{-12} \mathrm{e}$ $0,90 \times 10^{-12}$. A razão entre estes valores nos dará um valor de 2,7, que quando comparado com quase 18 do raio-x, nos fará acreditar que o poder dispersante da difração de neutrons é praticamente constante (ver Figura 13). Esta propriedade é a que determina uma excelente visualização dos átomos leves como o hidrogênio. Exemplo disto pode ser apreciado na Figura $11 \mathrm{~b}$.

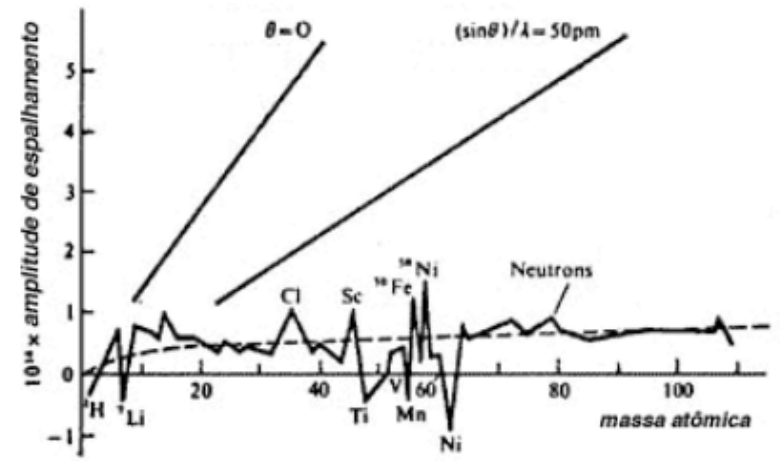

Figura 13 - Avaliação do poder dispersante dos neutrons para diferentes elementos químicos.

Com relação ao segundo tipo de espalhamento, a dispersão magnética, podemos dizer que os neutrons, por não apresentarem carga, não devem ser considerados como esferas inertes. Os neutrons, assim como os elétrons e prótons, apresentam um movimento de rotação próprio (spin), que gera um momento magnético sobre ele. Desta forma, se um átomo possuir um ou mais elétrons com spins desemparelhados, estes terão um momento magnético que, associado com o momento magnético do núcleo atômico, interagirá com o momento magnético do neutron a ser espalhado. Este espalhamento magnético é uma função do ângulo de espalhamento, do comprimento de onda do feixe de neutrons e do ângulo entre os momentos magnéticos.
Se o momento magnético dos neutrons incidentes ou se os neutrons dos átomos estiverem orientados aleatoriamente, a contribuição do espalhamento magnético não causará confusão no difratograma dos neutrons espalhado elasticamente, pois poderemos distinguir os dois casos pela dependência angular do espalhamento magnético. Se utilizarmos um feixe de neutrons polarizados, poderemos obter informações sobre a estrutura magnética dos cristais. Por exemplo, a Figura 14 mostra uma representação simplificada da estrutura magnética de um composto de cromo. Se utilizarmos raios-x ou difração elástica de neutrons, observaremos apenas que tal composto é cúbico de corpo centrado. Se utilizarmos neutrons polarizados conseguiremos distinguir os dois tipos de sistemas magnéticos.

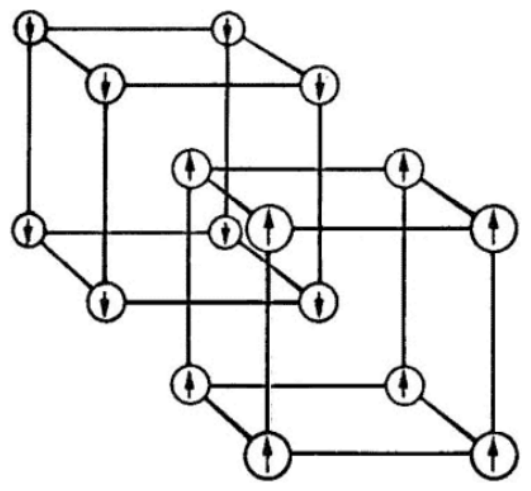

Figura 14 - Representação esquemática da estrutura magnética de um composto de cromo.

Finalmente, nos casos anteriores observamos que o método de difração de neutrons permitia obter detalhes das unidades tridimensionais de partículas em um cristal através da análise dos difratogramas, que apresentavam a característica de que as energias dos neutrons não se alteravam, como é o caso do espalhamento elástico e magnético. Entretanto, é possível que os neutrons ao se chocarem com os núcleos apresentem dispersões em que haja alguma transferência parcial de energia, resultando o que se chamou de dispersão inelástica. Esta perda ou ganho de energia dos neutrons ocorre através da mudança nas energias vibracionais do cristal em questão. Cálculos indicam que a magnitude de um quantum de energia suficiente para alterar os movimentos vibracionais em um cristal, apresenta a mesma ordem de energia que tem os neutrons incidentes. Medindo-se então as energias iniciais e finais dos neutrons, pode-se deduzir a energia das vibrações de cristais. Este efeito não é possível de ser observado com raios-x, pois estes apresentam uma energia 100.000 vezes maior do que os neutrons e, portanto, qualquer dispersão será desprezível. 
Com os neutrons, não se mede apenas a transferência de energia ao cristal, mas também o impulso e o sentido do movimento do fóton produzido.

Como podemos ver, a aplicação do método de difração de neutrons apresenta uma série de informações que não são disponíveis através de outras técnicas. Provavelmente o grande fator que limita sua aplicação, como já foi citado anteriormente, seja o fato de que tais medidas estão vinculadas a reatores nucleares. O que é uma limitação extremamente difícil de ser superada.

\section{Difração de elétrons}

Assim como geramos figuras de difração com neutrons, também é possível gerá-las com elétrons. A fonte de elétrons consiste em um cátodo aquecido, como os usados em aparelhos de televisão. Acelera-se estes elétrons através de uma diferença de potencial determinada e incide-se sobre a amostra. Aqui, encontramos a primeira diferença entre a dispersão de neutrons e elétrons. Estes últimos têm o comprimento de onda controlado pela diferença de potencial aplicado, o que permite controlar a energia do feixe. Outro aspecto é que utilizando-se uma combinação de campos elétricos e magnéticos poderemos focalizar o feixe em determinado ponto da amostra. Fato que não era possível nem com neutrons, nem com raios-x.

Elétrons, assim como os neutrons, são espalhados principalmente pelo campo elétrico dos núcleos atômicos, sendo sua dependência com a distância nuclear muito menor do que com os neutrons e raios-x. O que significa que sua capacidade de espalhamento é muito maior do que das outras duas técnicas. A consequência disto é que amostras para estudo de estruturas através de difração eletrônica são geralmente filmes muito finos ou camadas superficiais ou amostras extremamente diluídas, como é o caso de gases ou vapores.

Como podemos ver, a difração de elétrons, ao contrário da difração de neutrons e raios-x, não limita-se apenas ao estudo da geometria molecular em cristais, mas também em gases, e isto só foi possível com a disponibilidade de se controlar a energia do feixe. Para cada energia teremos uma aplicação diferente. Difração de elétrons de alta energia é comumente utilizada no estudo de sólidos. Difração de elétrons de baixa energia no estudo de superfícies e o caso intermediário, como sendo aquele aplicável no caso de vapores e gases.
Para este último caso, faz-se o feixe gasoso colidir perpendicularmente com o feixe de elétrons em uma câmara que procura estar continuamente evacuada. A figura de difração é recolhida em chapas fotográficas, onde se observa que a intensidade dos elétrons difratados cai rapidamente a medida que nos afastamos do feixe não-difratado.

A radiação difratada, que armazena a informação estrutural da substância gasosa, obedece uma relação chamada de equação de Wierl:

$$
I(\theta)=I_{0} K \sum_{i+j} Z_{i} Z_{j} \frac{\operatorname{sen}\left(s r_{i j}\right)}{s r_{i j}} \quad \text { equação (9) }
$$

onde $I_{0}$ é a intensidade do feixe de elétrons incidente, $\mathrm{K}$ é um fator de escala, $r_{i j}$ representa a distância entre os átomos $i$ e $j, Z_{\mathrm{i}}$ e $Z_{i}$ o número atômico desses átomos e $\mathrm{s}$ que é definido por $(4 \pi / \lambda) \operatorname{sen}(\theta / 2)$.

Na prática pode-se utilizar a Eq.9 através do método de tentativa e erro. Calcula-se $I(\theta)$ a partir de uma estrutura proposta e compara-se com o resultado experimental, repetindo-se o cálculo até os resultados coincidirem (ver Figura 15).
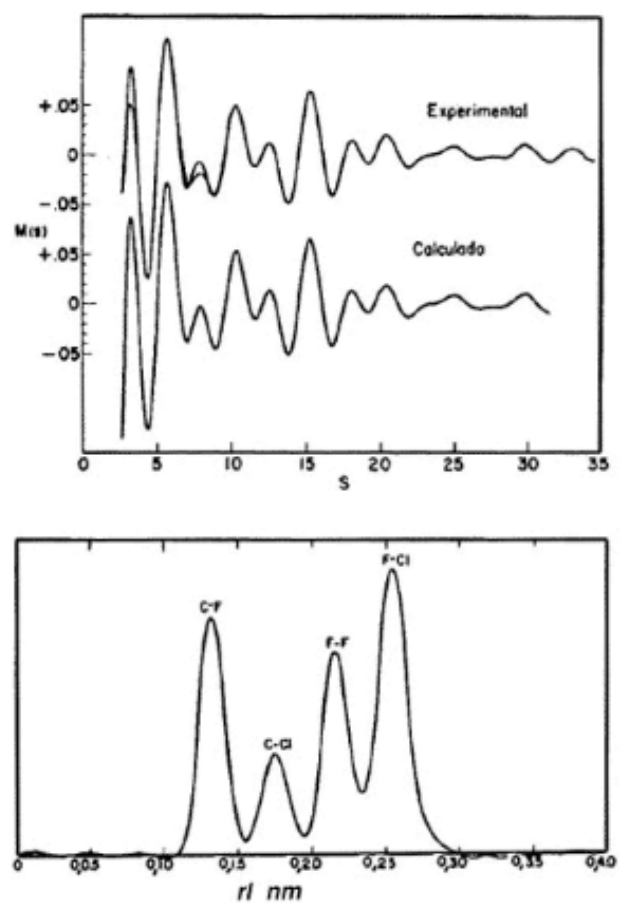

Figura 15 - Comparação do comportamento do $I(\theta)$ obtido teoricamente (a partir de uma estrutura proposta) com o resultado experimental.

Embora tal processo seja viável, é extremamente tedioso. 
Podemos, entretanto, estimar distâncias internucleares a partir da aplicação do método de Fourier. Para isto, temos que inicialmente imaginar que é possível substituir a função discreta dada pela Eq.9 por uma que varie continuamente, representando valores de distâncias interatômicas na molécula, $f(r)$. A Eq.9 é então reescrita como:

$$
I(s)=K^{\prime} \int_{0}^{\infty} f(r) \frac{\operatorname{sen}(s \cdot r)}{s \cdot r} d r \quad \text { equação }(10)
$$

Utilizando-se a transformação de Fourier obteremos:

$$
f(s)=K \int_{0}^{\infty} I(s) \frac{\operatorname{sen}(s \cdot r)}{s \cdot r} d r \quad \text { equação }(11)
$$

Experimentalmente obtemos o valor de $I(s)$, assim poderemos calcular o valor de $f(r)$, que quando colocado em um gráfico versus $r$ nos fornecerá as distâncias interatômicas da molécula (Figura 15). Como a integral da Eq.11 tem seu limite até $\infty$, devemos esperar algum erro na medida do comprimento e ângulo de cada ligação ou ainda uma sobreposição errônea de comprimentos de ligação, como é o caso mostrado na Figura 16.

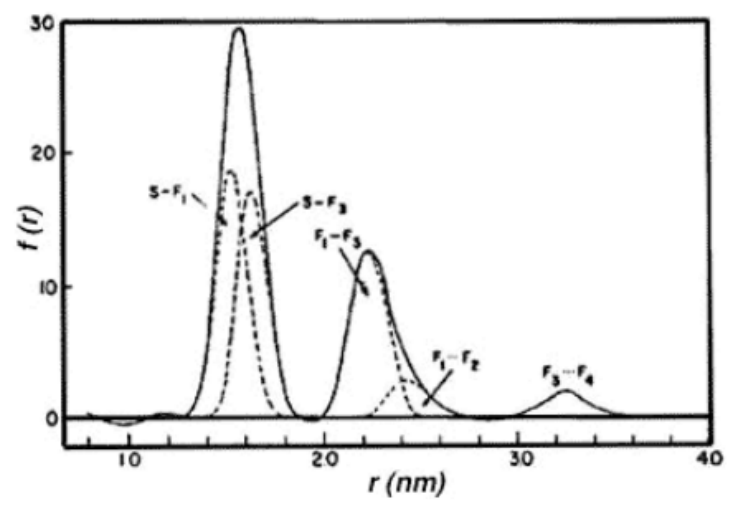

Figura 16 - Determinação dos parâmetros geométricos através de difração de elétrons.

$\mathrm{Na}$ tentativa de minimizar o erro das medidas, substituise a integral da Eq.11 por uma soma que possui um termo para cada mancha de difração:

$$
f(r)=\sum_{k} I_{k} \frac{\operatorname{sen}\left(s_{k} \cdot r\right)}{s_{k} \cdot r}
$$

onde: $\mathrm{I}_{\mathrm{k}}$ é a intensidade estimada para cada máximo e $\mathrm{s}_{\mathrm{k}}$ é o valor de s para o k-ésimo máximo.

Difração de elétrons de alta energia, normalmente
50 a $100 \mathrm{KeV}$ são analisados da mesma maneira. Instrumentalmente, ao invés de fazermos passar um feixe de gás perpendicularmente ao feixe de elétrons, colocamos um filme muito fino da amostra sólida no caminho do feixe. A análise dos difratogramas é feita da mesma maneira indicada acima.

Para elétrons de baixa energia, 30 a $600 \mathrm{eV}$, comumente utilizados em análise de processos de superfícies, não se faz com que o feixe eletrônico atravesse a amostra, mas sim que o mesmo seja refletido por sua superfície. Para análise de substâncias adsorvidas sobre metais, não-metais ou outros compostos, inicia-se o processo de análise pelo polimento da superfície do sólido. Isto requer polimentos especiais (químicos, eletroquímicos ou mecânicos) e vácuo da ordem de $10^{-9}$ torr. Terminada esta dificílima operação, procede-se a análise da mesma maneira citada acima.

\section{Métodos espectroscópicos}

No capítulo anterior preocupamo-nos com a medida dos parâmetros geométricos utilizando fontes de radiação que, ao interagirem com a matéria, propiciavam tal análise através do efeito de difração. Praticamente, a única fonte do espectro eletromagnético analisado foi a região dos raios-x. Como sabemos, o espectro eletromagnético é extremamente vasto e a interação de radiações de diferentes partes do espectro com substâncias produzem diferentes alterações no comportamento, bem como na estrutura molecular. Como estamos preocupados em determinar quantitativamente esses parâmetros geométricos, vamos procurar analisar as regiões do espectro eletromagnético mais utilizadas para este fim, que são a região de microondas e a região do infravermelho.

\section{Espectros de microondas}

Esta região do espectro está vinculada ao movimento rotacional molecular. Experimentalmente seu desenvolvimento tornou-se efetivo após a segunda guerra mundial com o desenvolvimento de osciladores contínuos de microondas. Sua aparelhagem apresenta as mesmas características de qualquer espectrômetro: fonte de radiação, cela de amostra e detector.

A fonte mais popular de microondas é conhecida pelo 
nome de klystron. A Figura 17 mostra um diagrama esquemático desta fonte. Ela contém um cátodo que produz elétrons por emissão térmica. $\mathrm{O}$ feixe de elétrons é levado a passar por uma cavidade ressonante que age como ânodo. Ao invés de colidirem com o ânodo, os elétrons passam diretamente pela cavidade no ânodo. $\mathrm{O}$ feixe sente então a influência de uma voltagem negativa existente em um eletrodo chamado de refletor, que força os elétrons a voltarem através da cavidade do ânodo. Sob certas condições de voltagem entre o ânodo e o refletor, o feixe de elétrons oscila na cavidade ressonante originando microondas, que são função do tamanho da cavidade e da voltagem do refletor.

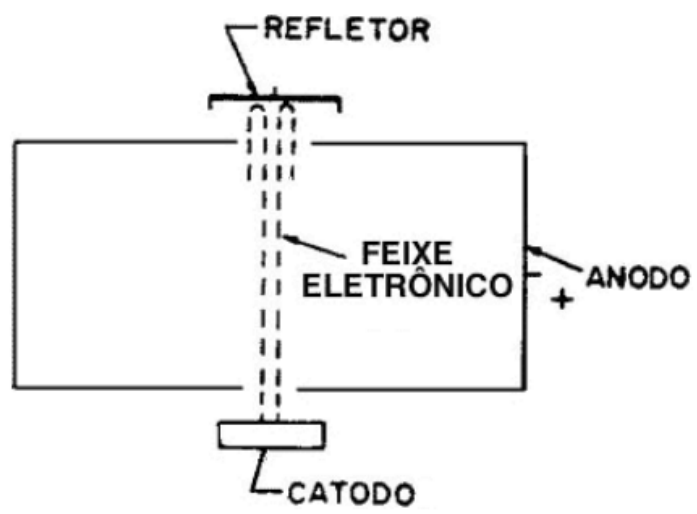

Figura 17 - Diagrama esquemático de uma fonte de microondas klystron.

O sinal de frequência é enviado para um detector através de um guia de ondas, que não passa de um tubo cilíndrico ou retangular, onde está contida a amostra gasosa. Os detectores mais comuns são simples cristais de silício. Não é necessário a utilização de monocromadores e as frequências são medidas com excelente precisão.

A aplicação desta espectroscopia no estado líquido e sólido é efetuada quando pretendemos conhecer a natureza e magnitude das interações intermoleculares. Para estudar geometria molecular, esta técnica é utilizada em substâncias gasosas ou que se encontrem no estado de vapor, geralmente em pressões muito baixas. Além desta exigência, devemos dizer que estas moléculas deverão apresentar momento dipolar permanente.

Como as pressões são extremamente baixas, podemos dizer que as moléculas no gás ou vapor possuem apenas energia cinética. Desconsiderando o movimento translacional e considerando apenas o movimento rotacional, podemos dizer que a energia da molécula será

$$
E=\sum_{i} \frac{1}{2} m_{i} v_{i}^{2}
$$

onde: $m_{i}$ representa a massa do i-ésimo átomo e $v_{i}$ a sua respectiva velocidade. Considerando-se que os átomos se deslocam em movimento angular em torno do centro de massa da molécula, podemos reescrever a Eq.13 como:

$$
E=\frac{\omega^{2}}{2} \sum_{i} m_{i} r_{i}^{2}
$$

equação (14)

sendo ri a distância do i-ésimo átomo com relação ao centro de massa no eixo de rotação e a sua velocidade angular $\sum_{i} m_{i} r_{i}^{2}$ é uma grandeza que recebe o nome de momento ${ }^{i}$ de inércia $(I)$ e que está relacionada com o momento angular da molécula $\left(P_{\text {rot }}\right)$ pela expressão:

$$
P_{\text {rot }}=I \omega
$$

equação (15)

Desta forma:

$$
E=\frac{\omega^{2}}{2} \sum_{i} m_{i} r_{i}^{2}
$$

Como o momento angular é limitado quanticamente a valores dados por:

$$
P_{r o t}=[j(j+1)]^{1 / 2} \frac{h}{2 \pi}=[j(j+1)]^{1 / 2} \hbar \quad \text { equação (17) }
$$

onde $\mathrm{j}=0,1,2, \ldots$, teremos que:

$$
E_{r o t}=\frac{I \omega^{2}}{2}=\frac{I^{2} \omega^{2}}{2 I}=\frac{j(j+1) \hbar^{2}}{2 I}
$$

Frequentemente simplifica-se a Eq.18 definindo-se um parâmetro conhecido como constante rotacional, que altera a forma da Eq. 18 para:

$$
E_{r o t}=B j(j+1)
$$

Sendo $B=\eta / 4 \pi I$. Outra característica quântica do espectro rotacional é que as transições são permitidas apenas entre niveis quânticos que apresentam uma diferença em j igual $\mathrm{a} \pm 1$.

A Eq.18 na verdade é uma forma simplificada da realidade atômica. Como estamos em um espaço tridimensional, esta equação será melhor descrita como

$$
E_{r o t}=\frac{p_{a}^{2}}{2 I_{a}}+\frac{p_{b}^{2}}{2 I_{b}}+\frac{p_{c}^{2}}{2 I_{c}}
$$
equação (20) 
sendo: $I_{a}, I_{b}$ e $I_{c}$ componentes do momento angular e $p_{a}$, $p_{b}$ e $p_{c}$ são componentes do momento angular total $p$, que é dado por

$$
p^{2}=p_{a}^{2}+p_{b}^{2}+p_{c}^{2}
$$

A Eq.21 pode ser simplificada em função do tipo de molécula que está sendo analisada. Desta forma, classificou-se as moléculas em quatro tipos principais:

a) esféricas quando $a=b=c$, assim:

$$
E_{r o t}=\frac{\left(p_{a}^{2}+p_{b}^{2}+p_{c}^{2}\right)}{2 I}=\frac{p^{2}}{2 I} \quad \text { equação }(22)
$$

b) lineares quando $I_{b}=I_{c}$ e $I_{a}=0$, assim:

$$
E_{\text {rot }}=\frac{\left(p_{a}^{2}+p_{b}^{2}+p_{c}^{2}\right)}{2 I}=\frac{p^{2}}{2 I} \quad \text { equação (23) }
$$

c) pião simétrico quando $I_{a} \neq I_{b}=I_{c}$. Este tipo de molécula é caracterizado por possuir um eixo de simetria principal $\mathrm{C} 3$ ou $\mathrm{C}(>3)$.

d) pião assimétrico quando $I_{a} \neq I_{b} \neq I_{c}$, onde encontram-se a maior parte das moléculas existentes na natureza.

Como podemos agora determinar os parâmetros geométricos das moléculas? Analisando o caso de uma molécula diatômica sabemos que a diferença de energia entre um estado $j$ para um $j+1$ é dado por

$$
\Delta E=h v=h B[(j+1)(j+2)-j(j+1)] \quad \text { equação }
$$

que, simplificando-se, é escrita como

$$
\Delta E=h v=2 h B(j+1) \quad \text { equação (25) }
$$

$v$ é a frequência observada e os outros dados são todos conhecidos, daqui poderemos calcular $B$ e, consequentemente, a distância internuclear através da Eq.20.

Moléculas lineares triatômicas têm duas distâncias interatômicas a serem determinadas:

$$
\mathrm{A} \stackrel{\mathrm{r}_{\mathrm{ab}}}{\mathrm{B}} \stackrel{\mathrm{r}_{\mathrm{ac}}}{ } \mathrm{C}
$$

Temos então uma equação (Eq.24) e duas incógnitas para determinar. Para resolvermos tal problema efetuamos substituições isotópicas na molécula. Este efeito manterá os comprimentos de ligação constantes, mas alterará as massas e, consequentemente, alterando também os momentos de inércia.

Determinando o espectro rotacional das duas moléculas obteremos equações para os momentos de inércia em termos de duas massas conhecidas e dois comprimentos de ligação desconhecidos, o que permite resolver facilmente o problema.

Para melhorarmos a qualidade das medidas, devemos introduzir um fator de correção que surge em função de distorções centrífugas. Este tipo de efeito torna-se mais pronunciado quando a molécula encontra-se em estados rotacionais excitados, ou melhor, de mais alta energia. A expressão para a energia rotacional para uma molécula diatômica torna-se então

$$
E_{r o t}=B_{0} j(j+1)-D j^{2}(j+1)^{2}
$$
equação (26)

onde $D$ é conhecida como constante centrífuga de distorção. Para interpretar o espectro, o valor de $B_{0}$ e $D$ são ajustados até que os valores calculados coincidam com os valores experimentais. Esta técnica é extremamente importante, quando não temos conhecimento das linhas do espectro em valores pequenos de $j$.

Experimentalmente, como poderemos fazer a atribuição de $j$ a uma determinada linha do espectro? Colocandose a molécula em um campo elétrico poderemos observar que as linhas principais do espectro são desdobradas em uma série de outras linhas. Este tipo de efeito é conhecido com o nome de efeito Stark. Sabe-se através da mecânica quântica que o número de linhas que aparecem em cada desdobramento depende de um segundo número quântico $m j$, que possui valores entre $-j$ e $+j$. Portanto, o número de linhas observadas deverá ser igual a $2 \mathrm{j}+1$. Com esta informação poderemos obter facilmente o valor de $\mathrm{j}$. A magnitude do efeito Stark depende apenas da força do campo elétrico e do momento dipolar da molécula. Sendo assim, tal técnica possibilita medidas desta quantidade também. Esta técnica torna-se extremamente útil quando nos deparamos com a análise de moléculas com pião simétrico e pião assimétrico.

Para o primeiro tipo, como vimos acima teremos $I_{a} \neq I_{b}$ $=I$. Como o momento angular total é quantizado temos que:

$$
p^{2}=j(j+1) \hbar^{2}=p_{a}^{2}+p_{b}^{2}+p_{c}^{2}
$$

equação (27) 
Observa-se também que:

$$
p_{a}^{2}=K^{2} \hbar^{2}
$$

onde: $K$ representa um novo número quântico, mostrando que a componente do momento angular $\left(\mathrm{P}_{\mathrm{a}}\right)$ ao longo do eixo de simetria principal é quantizado. $\mathrm{K}$ pode ter valores que variam de $+j \mathrm{a}-j$.

Combinando-se a Eq.29 com 28 obteremos o valor de $\mathrm{p}_{\mathrm{b}}^{2}+\mathrm{p}_{\mathrm{c}}^{2}$, finalizando com a equação:

$$
E_{r o t}=\frac{\left(k^{2} \hbar^{2}\right)}{2 I_{a}}+\frac{\left[j(j+1)-K^{2}\right] \hbar^{2}}{2 I_{b}} \text { equação (29) }
$$

Rearranjando e introduzindo as constantes rotacionais A e B, obtemos:

$$
\bar{v}=B j(j+1)+(A-B) K^{2} \quad \text { equação (30) }
$$

onde $\bar{v}$ representa o número de onda. A regra de seleção para uma transição rotacional deverá obedecer as seguintes condições: $\Delta j=0, \pm 1$ e $\Delta K=0$. Esta última surge porque o momento dipolar de uma molécula deste tipo coincide com o eixo de simetria de maior ordem e como o momento dipolar não possui componentes no plano perpendicular ao eixo de simetria, não teremos possibilidade de observar qualquer alteração rotacional neste plano. Como $K$ descreve exatamente a quantização da componente do momento angular no eixo principal, devemos esperar que $\Delta K=0$.

Para moléculas que possuem as características do pião assimétrico, os espectros rotacionais são comumente repletos de linhas. O momento angular é quantizado, mas não suas componentes. Mesmo na ausência de campo elétrico encontramos uma série de $2 j+1$ subníveis com diferentes energias. Entretanto, é possível derivar expressões para energias rotacionais de vários subníveis de um pião assimétrico em termos das três constantes rotacionais.

Em resumo, a técnica de microondas é uma técnica espectroscópica de alta precisão. Os fatores que limitam sua aplicabilidade são: a) necessidade de boa medida de massas atômicas, b) disponibilidade de substâncias isotopicamente substituídas e c) necessidade de que as substâncias a serem estudadas sejam gases ou vapores. A primeira restrição não é um fator determinante pois, com o desenvolvimento da espectrometria de massa, podemos determinar massas atômicas com alta precisão. O segundo aspecto é contornado pela alta sensibilidade da técnica, que permite detecção de espécies isotopicamente substituídas na amostra original, em alguns casos. $O$ terceiro fator também pode ser contornado pela possibilidade de se detectar o espectro de microondas em temperaturas elevadas.

O espectro de microondas só é possível de se obter para substâncias que possuam momento dipolar permanente. Mas poderemos obter informações do comportamento rotacional de qualquer molécula se estudarmos outras técnicas que produzam perturbações em moléculas apolares, gerando momentos dipolares temporários. Esta possibilidade será verificada na região do infravermelho.

Espectros na região do

infravermelho

Como vimos anteriormente, interação de microondas com moléculas que possuem momento dipolar permanente geram alterações detectáveis no comportamento rotacional dessas moléculas e através destas alterações podemos determinar parâmetros que definem a geometria molecular. Se começarmos a diminuir o comprimento de onda da radiação eletromagnética, atingiremos uma região conhecida como região do infravermelho. Este tipo de radiação, quando interage com moléculas, produz alteração no comportamento vibracional e rotacional da mesma e com esta perturbação poderemos obter alguma informação sobre a geometria molecular.

O esquema da instrumentação segue as mesmas linhas já discutidas anteriormente. Algumas sofisticações instrumentais dividem os espectrometros infravermelhos em aparelhos com: a) monofeixe, b) duplo feixe, c) transformada de Fourier e d) laser. Sendo que a precisão nas medidas aumenta na mesma sequência da apresentação, chegando a variar de $20 \mathrm{~cm}^{-1}$ nos aparelhos mais grosseiros até a $3 \times 10^{-3} \mathrm{~cm}^{-1}$ nos de altíssima precisão até o presente momento.

As fontes de radiação devem apresentar comportamento próximo ao do corpo negro. Comumente utiliza-se filamento de tungstênio, carbeto de silício, liga de níquelcromo, lâmpadas de mercúrio e, mais recentemente, lasers. Algumas dessas fontes operam mais eficientemente em determinadas faixas do espectro infravermelho.

As amostras podem ser sólidas, líquidas ou gasosas e para as amostras sólidas costuma-se prepará-las na forma de filmes ou utilizando a técnica de evaporação ou 
pastilhas.

$\mathrm{O}$ sistema de detecção consiste em qualquer instrumento que seja sensível a alterações de calor. Utiliza-se termopares, detectores pneumáticos ou piroelétricos (trissulfato de glicina, por exemplo) ou ainda efeitos óptico-acústicos.

Com a obtenção do espectro inicia-se a fase de interpretação do mesmo e posterior tentativa de inferir ou obter a geometria da molécula em estudo. Como o espectro na região do infravermelho corresponde àquele obtido por alterações no comportamento vibracional poderemos imaginar, de uma maneira bem grosseira, que os átomos em uma molécula são esferas rígidas unidas por pequenas molas que obedecem a lei de Hooke. Esta lei diz que a força de restauração à posição de equilíbrio de um sistema oscilante é diretamente proporcional ao deslocamento do ponto de equilíbrio, ou seja:

$$
\vec{F}=k \Delta \vec{x}
$$$$
\text { equação (31) }
$$

A constante $\mathrm{k}$ é uma medida da resistência ao movimento oscilatório. Um sistema que se comporta desta maneira é chamado de oscilador harmômico e pode-se mostrar que a frequência de suas oscilações é dada pela expressão:

$$
v=\frac{1}{2 \pi}\left(\frac{k}{m}\right)^{1 / 2}
$$

onde $\mathrm{m}$ é a massa do corpo que está se movendo. Para uma molécula diatômica substitui-se $\mathrm{m}$ pelo valor $\mathrm{da}$ massa reduzida, $\mathrm{m}_{1} \mathrm{~m}_{2} /\left(\mathrm{m}_{1}+\mathrm{m}_{2}\right)$.

Por intermédio da mecânica quântica podemos mostrar que os movimentos vibracionais também são quantizados e o cálculo de energia para o oscilador harmônico mostra que

$$
E_{n}=\left(n+\frac{1}{2}\right) h v
$$

sendo $\mathrm{n}$ um número inteiro que pode ser 0 ou qualquer valor inteiro, 1, 2, 3,... Observa-se ainda que as transições vibracionais permitidas para o oscilador harmônico são aquelas em que $\Delta n= \pm 1$. Bandas que obedecem a esta regra de seleção são chamadas de bandas fundamentais.

Entretanto, sabemos que nenhuma molécula apresenta perfeitamente o comportamento harmônico. Frequentemente nos deparamos com comportamentos que apresentam desvios em relação a este tipo de oscilador. Neste caso, dizemos que estamos na presença de um oscilador anarmônico. Para este caso, as regras de seleção permitem o aparecimento de transições onde: $\Delta \mathrm{n}= \pm 1, \pm 2$, $\pm 3, \ldots$ As transições com $\Delta \mathrm{n} \geq 2$ são comumente chamadas de sobretons e apresentam frequências que são 2, 3 ou $\Delta \mathrm{n}$ vezes maiores do que as frequências fundamentais. Estes comentários mostram de uma certa forma qual a natureza física dos espectros na região do infravermelho, mas não nos diz como podemos obter informações sobre a geometria molecular.

O procedimento qualitativo para se obter tal informação consiste em imaginar todos os arranjos possíveis dos átomos na molécula. Classificar cada uma das possíveis estruturas segundo seu grupo pontual derivado pela teoria de grupo. Através desta caracterização podemos identificar quantos e de que tipo são os graus de liberdade e quantas bandas no infravermelho terão possibilidade de serem observadas. Obtém-se experimentalmente o espectro vibracional da molécula e procura-se identificar as bandas fundamentais, dos sobretons, das bandas de combinação e conta-se quantas são as fundamentais. Comparandose com aquelas previstas pela teoria de grupo, teremos informações de como deve ser a distribuição dos átomos na molécula.

O grande problema experimental seria a metodologia para fazer-se a atribuição das bandas. Não existe nenhum critério rigoroso para se efetuar tal medida. Esta etapa é realizada através de comparações entre espectros de várias moléculas ou ainda efetuando comparações com moléculas isotopicamente substituídas ou comparando-se com espectros obtidos através do método Raman. Podemos ainda criar um campo de força e tentar reproduzir as frequências vibracionais através de métodos matemáticos. Dentre estes métodos é possível ajustar-se constantes de força para diferentes tipos de ligação química e, com estas constantes, calcular-se os parâmetros geométricos, como ocorre nos métodos conhecidos como mecânica molecular.

Resumidamente, podemos dizer que a atribuição de bandas vibracionais é realizada de uma maneira muito vaga e a necessidade de um método sistemático para resolver o problema seria uma ferramenta muito bem recebida para os pesquisadores interessados em estruturas moleculares. Poderíamos ficar desapontados com a técnica de infravermelho que não nos fornece dados quantitativos para a geometria molecular, mas uma análise mais minuciosa do espectro de infravermelho nos dará informações que nos serão úteis.

A melhor resolução das bandas de um composto gasoso na região do infravermelho mostra-nos que esta é 
composta de uma série de pequenas bandas como as da Figura 18. Estas pequenas bandas mostram que os movimentos vibracionais são usualmente acompanhados por mudanças nos estados rotacionais e, como já vimos, com informações de transições rotacionais poderemos avaliar as constantes rotacionais e consequentemente os parâmetros que determinam a geometria molecular.

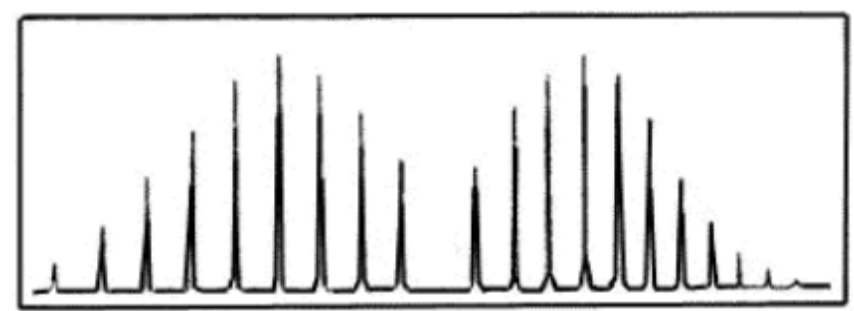

Figura 18 - Aparência de uma banda vibracional para moléculas diatômicas. Considerando-se que a freqüência cresce da esquerda para a direita, pode-se observar que a banda é constituída por dois conjuntos de transições. $O$ conjunto de picos a esquerda corresponde ao ramo $R$ e o conjunto a direita ao ramo $P$.

Poderíamos perguntar: qual seria a vantagem de se obter informações rotacionais do espectro infravermelho, se podemos obter informações precisas de espectros de microondas? Devemos nos lembrar que os espectros rotacionais são obtidos apenas para moléculas que possuam momento dipolar permanente. Logo, moléculas como metano $\left(\mathrm{CH}_{4}\right)$ ou gás carbônico $\left(\mathrm{CO}_{2}\right)$ não mostrariam qualquer absorção ou emissão na região de microondas, o que nos impossibilitaria determinar as respectivas geometrias quantitativamente. $\mathrm{Na}$ região do infravermelho, o que se observa é que as bandas espectrais aparecem como consequência de alterações no momento dipolar molecular. Portanto, moléculas que não possuem momento dipolar permanente, ao executarem certos movimentos vibracionais, adquirem um certo momento dipolar que consegue imprimir alterações no movimento rotacional da molécula.

Para o movimento rotacional, as regras de seleção $\Delta \mathrm{j}=0$, \pm 1 continuam sendo válidas. Comumente estas transições recebem nomes especiais na região do infravermelho: -1 chama-se de ramo $\mathrm{P}$ e encontra-se em frequências maiores, +1 é chamado de ramo $\mathrm{R}$ que encontra-se na região de frequências menores e o ramo $Q$ que aparece como um pico agudo entre os ramos $\mathrm{P}$ e R. A Figura 18 mostra o exemplo de ramos $\mathrm{R}$ e $\mathrm{P}$ e a Figura 19 as transições rotacionais entre dois níveis vibracionais. Diferenças nas alturas dos picos rotacionais são consequência das diferentes populações em cada nível rotacional. A análise nesta etapa segue os mesmos moldes desenvolvidos no item de microondas.

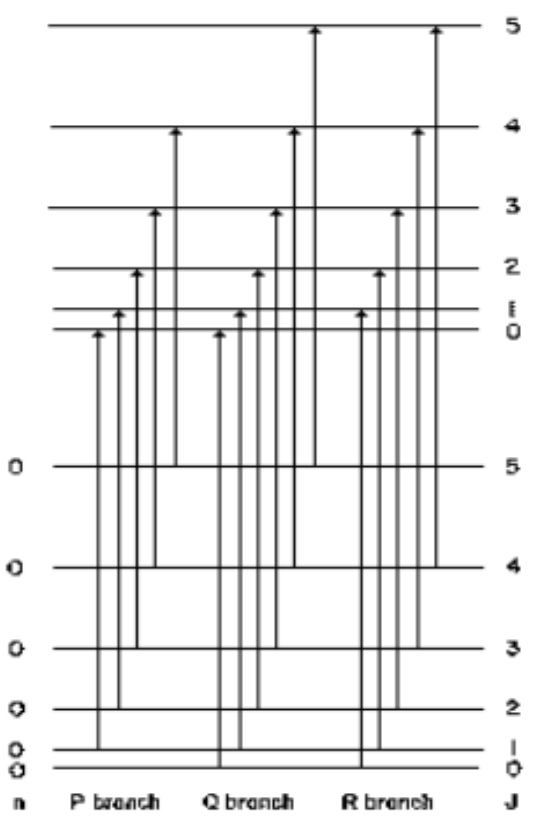

Figura 19 - Algumas das possíveis transições a partir de um estado vibracional de menor energia para um de maior energia.

Considerando que alterações no movimento vibracional alterarão os parâmetros geométricos, devemos procurar corrigir os valores das constantes rotacionais de tal maneira que obtenhamos valores para estas constantes que estejam próximos das vibrações do estado fundamental.

\section{Considerações finais}

Nesta rápida revisão foram apresentados e discutidos aspectos básicos relacionados a alguns métodos empregados na determinação da geometria de moléculas. Escolhemos apenas cinco métodos por serem estes os que determinam uma obtenção quase que direta desses parâmetros. Observando-se o espectro eletromagnético, verificamos que ainda há uma grande região não discutida, mas que também pode oferecer informações sobre a estrutura de moléculas.

Comparando-se os métodos já discutidos, nos perguntamos: qual seria o melhor método para a finalidade proposta? $\mathrm{Na}$ verdade, não se pode dizer que existe um método que seja melhor do que outro. Podemos dizer que existem certos métodos que se prestam melhor a certas condições. Os fatores que determinarão a maior ou menor utilização de um determinado método podem ser resumindos em cinco ítens:

- estado físico da substância 
- precisão

- custo operacional

- acesso ao método

- complexidade da molécula

A primeira observação é quase que evidente pois, como já discutimos, alguns métodos podem ser aplicados apenas à substância no estado gasoso. Outros são aplicáveis a substâncias no estado sólido ou líquido.

Se estivermos realizando pesquisa acadêmica, o terceiro item pode não possuir tanta importância, pois procura-se neste caso atingir-se um fim sem que muitas vezes seja observada esta limitação, fato que não ocorre em pesquisa industrial onde o custo operacional também deve ser considerado.

Outro aspecto que diz respeito ao acesso, talvez seja um dos fatores que mais limitam o uso de certas técnicas. Por exemplo, a técnica de difração de neutrons é uma das mais interessantes e precisas para resolver certos problemas, como já foi discutido anteriormente. Entretanto, seu acesso é extremamente limitado, o que nos leva frequentemente a procurar métodos mais acessíveis, como raios-x ou métodos espectroscópicos.

Finalmente, para moléculas relativamente simples, poderemos utilizar os métodos espectroscópicos e obter parâmetros geométricos com altíssima precisão. Se tivermos moléculas muito complicadas deveremos utilizar raios- $x$, sabendo-se que, neste caso, perderemos precisão nas medidas pela alta complexidade do problema. 